\title{
Heart rate variability under resting conditions in postmenopausal and young women
}

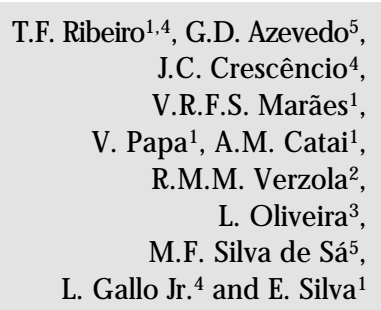

\author{
'Laboratório de Fisioterapia Cardiovascular, Departamento de Fisioterapia, \\ 2Departamento de Ciências Fisiológicas and ${ }^{3}$ Departamento de Física, \\ Universidade Federal de São Carlos, São Carlos, SP, Brasil \\ ${ }^{4}$ Divisão de Cardiologia, Departamento de Clínica M édica, and \\ ${ }^{5}$ Departamento de Ginecologia e Obstetrícia, \\ Faculdade de Medicina de Ribeirão Preto, Universidade de São Paulo, \\ Ribeirão Preto, SP, Brasil
}

\section{Correspondence \\ E. da Silva \\ Laboratório de Fisioterapia \\ Cardiovascular \\ Departamento de Fisioterapia, UFSCar Rodovia Washington Luís, km 235 \\ 13565-905 São Carlos, SP \\ Brasil \\ E-mail: esters@ power.ufscar.br}

Research supported by CAPES, CNPq (Nos. 300528/85 and 520686/95) and FAPESP (No. 98/13257-8).

Received May 15, 2000

Accepted March 2, 2001

\section{Abstract}

The aim of the present study was to compare the modulation of heart rate in a group of postmenopausal women to that of a group of young women under resting conditions on the basis of R-R interval variability. Ten healthy postmenopausal women (mean $\pm \mathrm{SD}, 58.3 \pm 6.8$ years) and 10 healthy young women (mean $\pm \mathrm{SD}, 21.6 \pm 0.82$ years) were submitted to a control resting electrocardiogram (ECG) in the supine and sitting positions over a period of $6 \mathrm{~min}$. The ECG was obtained from a one-channel heart monitor at the CM5 lead and processed and stored using an analog to digital converter connected to a microcomputer. R-R intervals were calculated on a beat-to-beat basis from the ECG recording in real time using a signal-processing software. Heart rate variability (HRV) was expressed as standard deviation (RMSM) and mean square root (RMSSD). In the supine position, the postmenopausal group showed significantly lower $(\mathrm{P}<0.05)$ median values of RMSM (34.9) and RMSSD (22.32) than the young group (RMSM: 62.11 and RMSSD: 49.1). The same occurred in the sitting position (RMSM: 33.0 and RMSSD: 18.9 compared to RMSM: 57.6 and RMSSD: 42.8 for the young group). These results indicate a decrease in parasympathetic modulation in postmenopausal women compared to young women which was possibly due both to the influence of age and hormonal factors. Thus, time domain HRV proved to be a noninvasive and sensitive method for the identification of changes in autonomic modulation of the sinus node in postmenopausal women.

\section{Introduction}

The heart is an organ under the influence of the autonomic nervous system for the maintenance of homeostasis, and, in this respect, one of its main characteristics is the constant modification of its rate on beat-tobeat basis $(1,2)$.

\section{Key words}

- Heart rate variability

- Menopause

- Autonomic nervous system

- Time domain indexes 
recordings (3-5). This method has proved to be of great clinical usefulness to evaluate the balance of sympathetic and parasympathetic regulation in several pathological conditions (6-12). HRV has proved to be a more sensitive tool for the detection of autonomic balance than mean heart rate (HR) (9).

The so-called measures in the time domain are indexes obtained from a continuous ECG recording, which are used to determine the dispersion of the duration of the $\mathrm{R}$ wave intervals among its mean or a reference value. The various indexes proposed for the measurement of HRV in the time domain can be divided into three types: arithmetic, geometric or statistical calculations $(2,10,11)$.

A study of healthy volunteers using pharmacological blockade with atropine documented a statistically significant reduction in some HRV indexes in the time domain, a fact that was not observed after blockade with propranolol (13). These investigators concluded that there is a correlation between temporal variability indexes and vagal tonus acting on the sinus node.

On the other hand, in patients with heart disease, reduced HRV has been associated with the occurrence of ventricular arrhythmias, such as ventricular fibrillation and increased mortality $(9,10)$. The prevalence of cardiovascular diseases increases with advancing age in women, especially after menopause and among those with a sedentary life style (14-16). Few studies have evaluated neurocardiac parameters during the various phases of women's life for the determination of risk factors, a procedure that would be useful and highly relevant for cardiovascular evaluation of women at higher risk to develop heart disease, thus permitting early intervention.

Analysis of the HRV response can be used to evaluate the adaptations of the autonomic nervous system in women related to changes due to aging and to the decreased beneficial effects of natural estrogen on the heart.
The objective of the present study was to compare time domain HRV between postmenopausal and young women under supine and sitting resting conditions.

\section{Methods}

The study was conducted on 10 young volunteers and 10 postmenopausal volunteers who were not on hormone replacement therapy. Their anthropometric characteristics, reported as mean and standard deviations, were: age $21.6 \pm 0.82$ years, weight $56.3 \pm 6.62 \mathrm{~kg}$, and height $161.6 \pm 4.74 \mathrm{~cm}$, and age $58.3 \pm 6.8$ years, weight $65.2 \pm 12.11$ $\mathrm{kg}$, and height $156.3 \pm 5.51 \mathrm{~cm}$, respectively. Both groups were composed of healthy nonsmoking women with a sedentary life style; the volunteers were not taking any medications. Before the study the volunteers were submitted to clinical and laboratory examinations, including a resting ECG and dynamic exercise seated on a cycle ergometer until they reached a target heart rate corrected for age; this last test was used to include in the study only women without ischemic heart disease.

The study was approved by the Ethics Committee of Universidade Federal de São Carlos and the volunteers gave written informed consent to participate in the study.

The experiments were carried out in a specially acclimatized room at $22^{\circ} \mathrm{C}$ and $60 \%$ humidity, always at the same time of day in order to avoid response differences due to circadian changes. The volunteers were monitored at the CM5 lead under resting conditions in the supine and sitting positions. The ECG and HR were obtained from a onechannel heart monitor (ECAFIX TC500) and processed using an analog-digital converter Lab. PC+ (National Instruments, Co., Austin, TX, USA), which represents an interface between the heart monitor and a Pentium II microcomputer. Starting from the identification of " $R$ " peaks of the ECG waves, the R$\mathrm{R}$ intervals were calculated on a beat-to-beat 
basis from the ECG using a signal-processing software (5). Systemic arterial pressure was measured using a mercury column sphygmomanometer under resting conditions in the supine and sitting positions. For the young group, the recordings were always obtained during the same period of the menstrual cycle, i.e., between the 8th and the 10th day of the cycle. R-R intervals were recorded over a period of 6 min under resting conditions in the supine and sitting positions and are shown in Figures 1 and 2, respectively.

Two indexes were used for the measurement of HRV, i.e., the standard deviations of R-R intervals (RMSM or SDNN), and the square root of the mean of the squared differences between adjacent normal R-R intervals (RMSSD). RMSM corresponds to the square root of the sum of squares of the differences of individual values in relation to the mean value divided by the number of $\mathrm{R}-\mathrm{R}$ intervals within a given time (Equation 1). RMSSD corresponds to the square root of the mean sum of squares of the differences between the adjacent normal R-R intervals in the record divided by the number of R-R intervals within a given time minus one R-R interval (Equation 2) (17).

$\mathrm{RMSM}=\sqrt{\frac{\sum_{\mathrm{i}=1}^{\mathrm{N}}\left(\mathrm{RR}_{\mathrm{i}}-\overline{\mathrm{RR}}\right)^{2}}{\mathrm{~N}}}$

Eq. 1

$\mathrm{RMSSD}=\sqrt{\frac{\sum_{\mathrm{i}=1}^{\mathrm{N}-1}\left(\mathrm{RR}_{\mathrm{i}}-\mathrm{RR}_{\mathrm{i}+1}\right)^{2}}{\mathrm{~N}-1}}$

Eq. 2

where $\mathrm{N}=$ number of $\mathrm{R}-\mathrm{R}$ intervals in the series of selected data.

The Graphic Electrocardiogram Analyzer, an application developed at the Laboratório de Fisioterapia Cardiovascular, Universidade Federal de São Carlos, was used to obtain the variability indexes.

\section{Results}

Table 1 shows the anthropometric characteristics, body mass index, and clinical and hormonal determinations for the studied volunteers.

The results are presented in box plots as

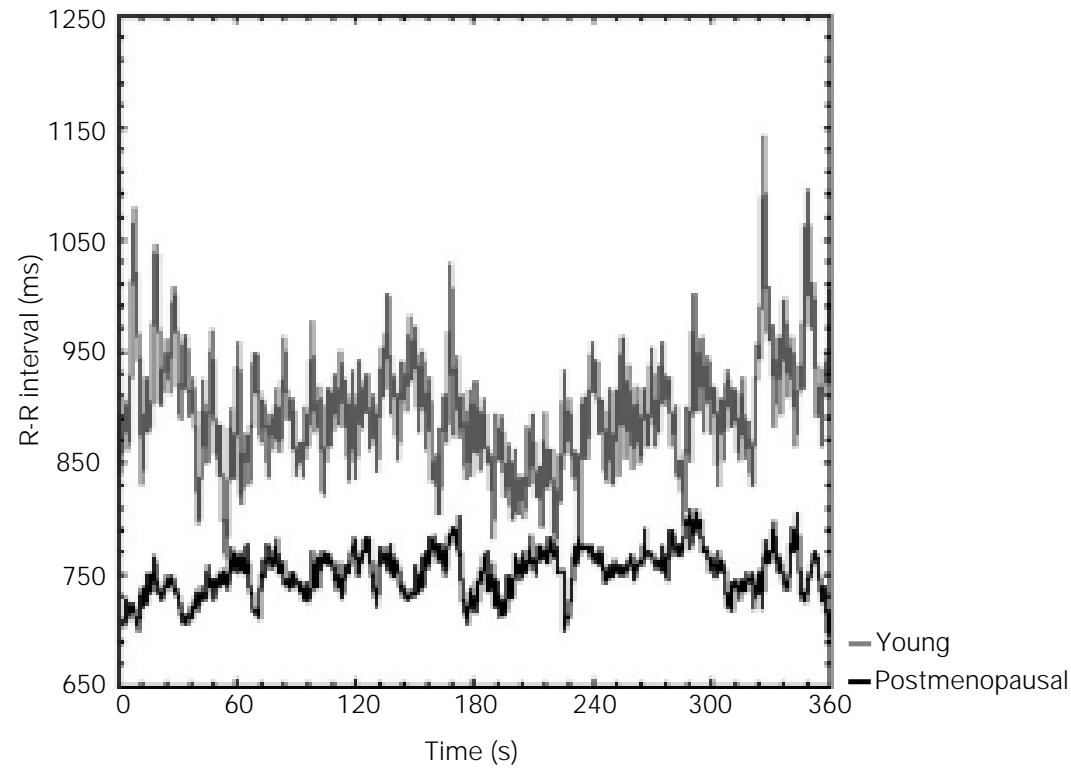

Figure 1. R-R interval, in ms, for the young (gray) and postmenopausal (black) volunteers under resting conditions in the supine position $(\mathrm{N}=2)$.

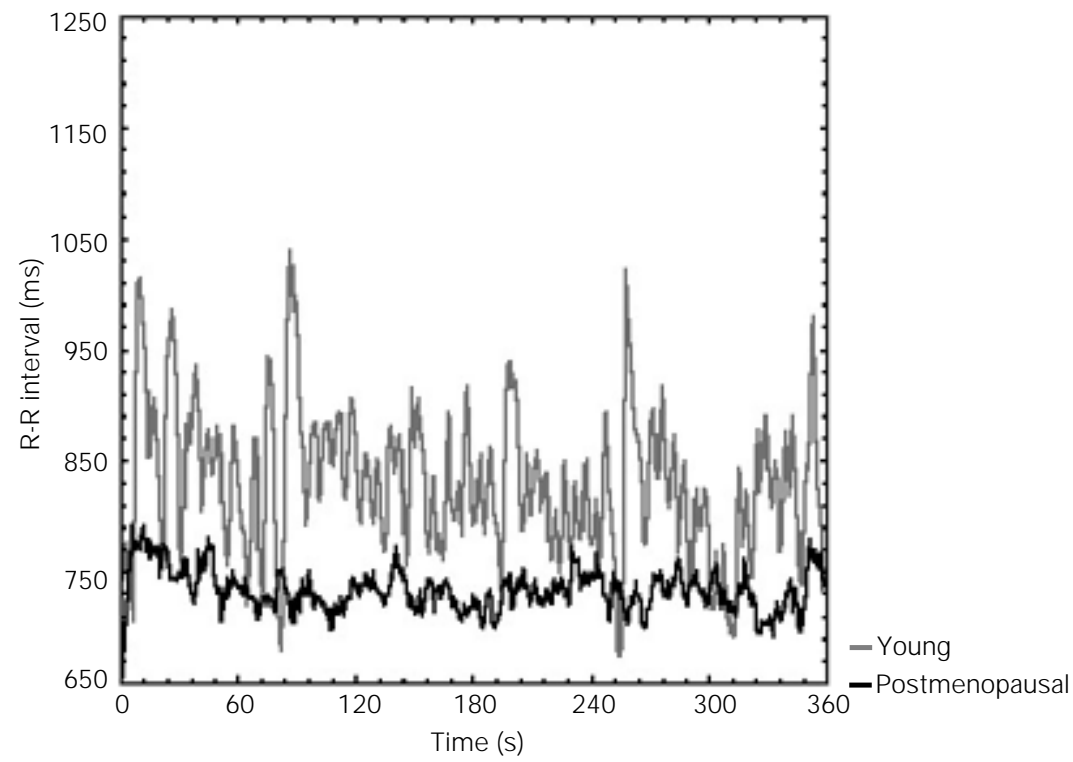

Figure 2. R-R interval, in ms, for the young (gray) and postmenopausal (black) volunteers under resting conditions in the sitting position $(\mathrm{N}=2)$. 
Table 1. Anthropometric, clinical and hormonal characteristics of the groups studied.

\begin{tabular}{lrc}
\hline Characteristic & \multicolumn{1}{c}{ Young } & Postmenopausal \\
\hline Age (years) & $21.6 \pm 0.82$ & $58.3 \pm 6.8^{* *}$ \\
Height $(\mathrm{cm})$ & $161.6 \pm 4.74$ & $156.3 \pm 5.51^{*}$ \\
Weight $(\mathrm{kg})$ & $56.3 \pm 6.62$ & $65.2 \pm 12.11^{*}$ \\
Body mass index $\left(\mathrm{kg} / \mathrm{m}^{2}\right)$ & $21.4 \pm 1.43$ & $23.2 \pm 6.42$ \\
Systolic blood pressure $(\mathrm{mmHg})$ & $108.2 \pm 8.45$ & $124.6 \pm 14.6^{* *}$ \\
Diastolic blood pressure $(\mathrm{mmHg})$ & $71.4 \pm 7.44$ & $78.5 \pm 9.07^{*}$ \\
Follicle-stimulating hormone level $(\mathrm{mlU} / \mathrm{ml})$ & $4.8 \pm 0.78$ & $79.1 \pm 35.54^{* *}$ \\
Luteinizing hormone level $(\mathrm{mlU} / \mathrm{ml})$ & $3.1 \pm 0.76$ & $22.1 \pm 10.66^{* *}$ \\
Prolactin level $(\mathrm{ng} / \mathrm{ml})$ & $11.6 \pm 5.48$ & $4.5 \pm 1.71^{* *}$ \\
Serum estradiol level $(\mathrm{pg} / \mathrm{ml})$ & $43.7 \pm 8.23$ & $<20^{\text {a* }}$ \\
\hline
\end{tabular}

Values are reported as means \pm SD. aLower concentration of assay standard curve. $\mathrm{N}=$ 10 for each group. $* \mathrm{P}<0.05$ and $* * \mathrm{P}<0.001$ compared to young volunteers (MannWhitney test).

Figure 3. RMSM indexes, the standard deviation of R-R intervals, in $\mathrm{ms}$, for the young group $(\mathrm{N}=10)$ and the postmenopausal group $(\mathrm{N}=10)$ under resting conditions in the supine and sitting positions.

Figure 4. RMSSD indexes, the square root of the mean of the squared differences between adjacent normal $\mathrm{R}-\mathrm{R}$ intervals, in $\mathrm{ms}$, for the young group $(\mathrm{N}=10)$ and the postmenopausal group $(\mathrm{N}=10)$ under resting conditions in the supine and sitting positions.
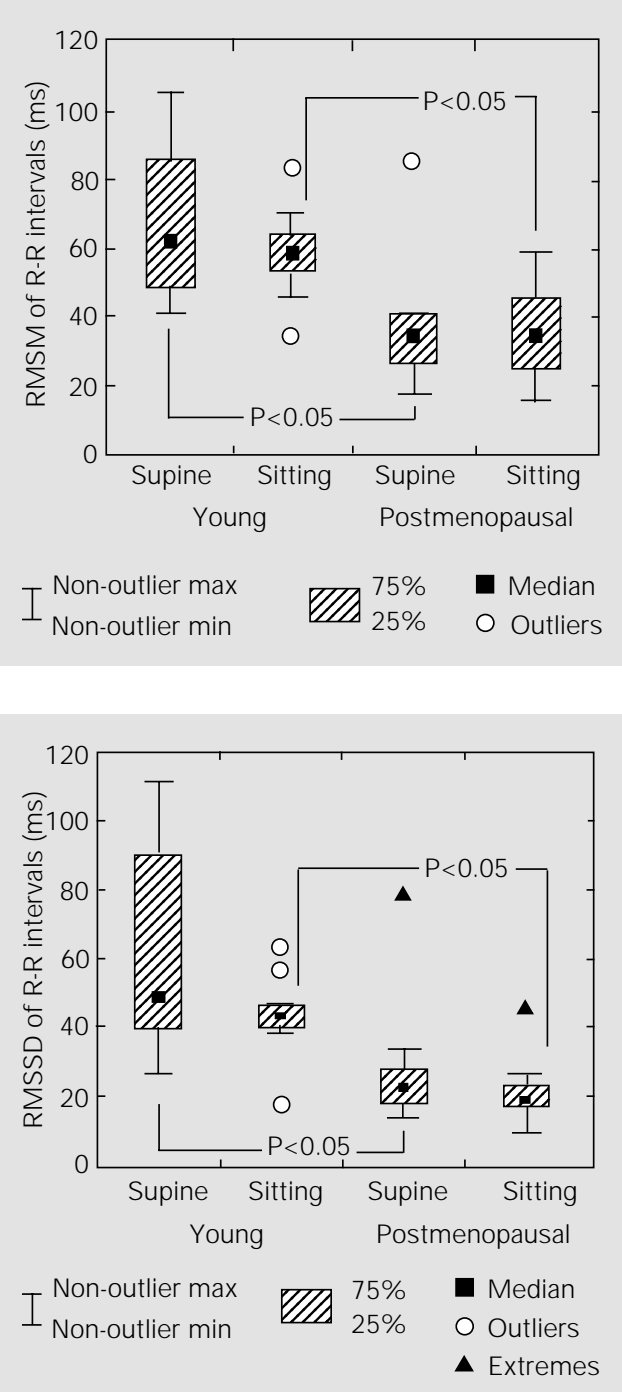

median, 1st and 3rd quartiles and outliers. Data were analyzed statistically by the nonparametric Mann-Whitney test for intergroup comparison and by the Wilcoxon rank test for intragroup analysis, with the level of significance set at $\mathrm{P}<0.05$. The analysis was carried out using the Statistic for Windows software, release 5.1. StatSoft, Inc., 19941996.

Figures 3 and 4 illustrate the analysis of HRV expressed as RMSM and RMSSD indexes of R-R interval variability obtained for the groups of postmenopausal and young volunteers under resting conditions in the supine and sitting positions. Intergroup analysis showed significant differences $(\mathrm{P}<0.05)$, with lower RMSM and RMSSD indexes in the menopausal group compared to the young one. However, intragroup analysis showed no significant differences $(\mathrm{P}>0.05)$ in HRV indexes (RMSM and RMSSD) in the supine or seated position. Figure 5 shows that there was no significant difference $(\mathrm{P}>0.05)$ in mean HR between the groups.

\section{Discussion}

Autonomic modulation is the main mechanism responsible for HR control in normal volunteers. In this context, stimulation of the parasympathetic nerves is associated with a decrease in HR and an increase in its variability, whereas stimulation of the sympathetic system is associated with an increase in HR and a decrease in HR variability $(18,19)$. Under resting conditions, both the sympathetic and parasympathetic systems are tonically active, with a predominant vagal effect $(1,2,11,18,19)$.

The literature has reported the use of a great variety of different HRV indexes. However, it has not been definitely proved that any one of these indexes is superior to another $(1,2,11,17)$.

The selection of the RMSM and RMSSD in this study was based on the relatively high sensitivity of these indexes due to the use of 
squares of the differences (17). The choice of a 6-min recording period for assessment of HRV, i.e., the so-called short-term assessment, was based on the fact that this time interval is sufficient to allow a full stabilization of R-R interval variability, as reported in most studies in this area $(2,20,21)$. Finally, compared to frequency domain indexes, time domain indexes are less restrictive in terms of the occurrence of nonlinearity, particularly when different age groups are compared $(2,11)$.

Several studies have shown that HRV declines with age in both sexes. The relatively greater high frequency component of total variability reported in women in the age range of 35 to 65 years may be responsible for the overall protection of women compared to men against coronary heart disease, and in particular coronary mortality and sudden cardiac death in this age range. Also, the present study confirms the loss of heart protection in postmenopausal women. A possible protective mechanism in younger women could be the reduction of arrhythmias related to enhanced vagal activity $(14,21)$.

However, different results related to the aging and gender effects of HRV have been reported in other studies. Some investigators (22), using a methodology similar to ours for the evaluation of young men and middleaged men with active life styles, found no significant differences in HRV indexes (RMSM and RMSSD) related to body position, indicating that the vagal-sympathetic modulation was unchanged under these conditions. In another recent study (14), the authors observed that HRV (time and frequency domain measures) declined with advancing age in healthy sedentary and physically active women, suggesting that a reduction in HRV with age may be an inevitable consequence of the aging process; however, HRV was significantly higher in physically active women at any age.

In the present study the decrease in HRV

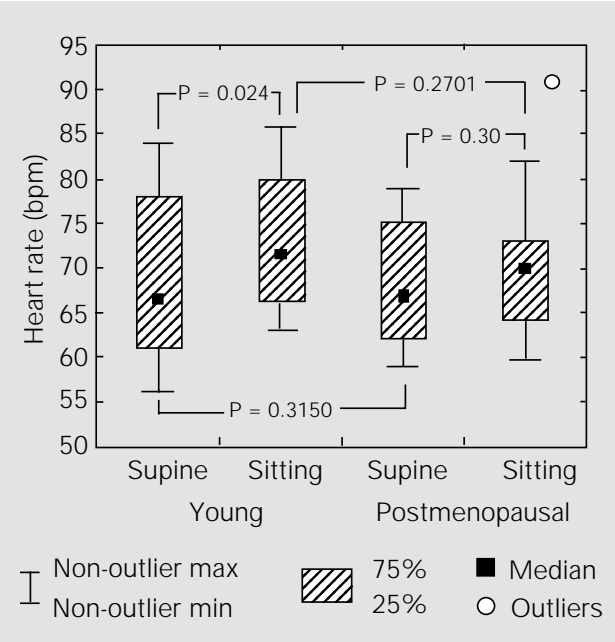

Figure 5. Mean heart rate, in bpm over a period of 6 min for the young group $(\mathrm{N}=10)$ and the postmenopausal group $(\mathrm{N}=$ 10) under resting conditions in the supine and sitting positions. observed in sedentary postmenopausal women was significant, reflecting the influence of age, possibly associated with physical inactivity and deficient hormonal production. The design of our study did not allow us to quantify the participation of each of these mechanisms in the HRV changes observed in menopause women.

Based on epidemiological data indicating a significant increase in the incidence of cardiovascular disease in postmenopausal women, several studies have been conducted in order to determine the effects of hypoestrogenism on cardiovascular physiology, as well as the probable benefits of hormonal replacement for the prevention of these diseases.

Many observational studies have found lower rates of coronary heart disease in women who take postmenopausal estrogen than in women not receiving this therapy $(15,23)$. However, the results of a randomized, blind, placebo-controlled trial (HERS study) did not demonstrate any benefit of hormonal replacement in terms of the secondary prevention of cardiovascular events. During an average follow-up of 4.1 years, treatment with oral conjugated equine estrogen plus medroxyprogesterone acetate did not reduce the overall rate of coronary heart disease events in postmenopausal women with established coronary disease (16). 
So far, little is known about the modulation of HRV by hormone replacement therapy in postmenopausal women. HRV has been shown to be increased by $17 ß$-estradiol in an uncontrolled clinical study (24), a finding that could at least partly explain the potential cardioprotective estrogen actions (25).

A study by Christ et al. (25) demonstrated that hormone replacement therapy containing progestins may attenuate HRV in healthy postmenopausal women. Thus, the addition of progestins to hormone replacement therapy may outweigh the postulated beneficial effects of estrogens on cardiovascular risk. These observations may explain at least in part the disappointing results of the HERS study (25).

The decrease in HRV is related to a reduction in parasympathetic activity with advancing age $(21,22)$. Although the mechanism underlying this finding has not been clearly defined, there is experimental evidence of a protective effect of vagal stimulation against electrical ventricular vulnerability, in addition to other more complex mechanisms that might explain the relation- ship between HRV and mortality due to cardiac events (10). Thus, compared with young subjects of similar activity status, postmenopausal women may be at an additional risk (i.e., beyond that due to aging itself) (14).

Considering of all these reports, time domain HRV estimated by ECG monitoring may offer important information on the autonomic control of the heart in addition to that obtained by a traditional evaluation of risk factors. Thus, HRV can be considered a relatively simple, noninvasive and sensitive method for studying autonomic modulation of sinus node compared to others that measure only average HR values under basal conditions and in the presence of a physiological stimulus.

Our data indicate a decrease in HRV that seems to be an expression of a reduction in autonomic modulation in postmenopausal women compared to young women, which most likely was due to the decrease in parasympathetic modulation in sinus node. This decrease can be the result of an age effect, possibly associated with hormonal factors.

\section{References}

1. Longo A, Ferreira D \& Correia MJ (1995). Variabilidade da freqüência cardíaca. Revista Portuguesa de Cardiologia, 14: 241262.

2. Task Force of the European Society of Cardiology of the North American Society of Pacing Electrophysiology (1996). Heart rate variability standards of measurement, physiological interpretation, and clinical use. Circulation, 93: 1043-1065.

3. Pagani M, Lombardi F, Guzzetti S, Rimoldi $O$, Furlan R, Pizzineli $P$, Sandrome $G$, Malfatto G, Dell'orto S, Piccaluga E, Turiel M, Baselli G \& Malliani A (1986). Power spectral analysis of heart rate and arterial pressure variabilities as a marker of sympathovagal interaction in man and conscious dog. Circulation, 59: 178-193.

4. Ribbert LS, Fidler V \& Visser GH (1991). Computer-assisted analysis of normal second trimester fetal heart rate patterns. J ournal of Perinatal Medicine, 19: 53-59.
5. Silva E, Catai AM, Trevelin LC, Guimarães J O, Silva J $r$ LP, Silva LMP, Oliveira L, Millan LA, Martins LEB \& Gallo J r L (1994). Design of a computerized system to evaluate the cardiac function during dynamic exercise. Physics in Medicine and Biology, 33: 409 (Abstract).

6. Tiller WA, McCraty $R \&$ Atkinson $M$ (1996). Cardiac coherence: a new noninvasive measure of autonomic nervous system order. Alternative Therapies in Health and Medicine, 2: 52-65.

7. Lindqvist A (1990). Noninvasive methods to study autonomic nervous control of circulation. Acta Physiologica Scandinavica, 588 (Suppl): 1-107.

8. J esus PC (1996). Considerações metodológicas e caracterização de procedimentos implicados nas análises temporal e espectral da variabilidade da freqüência cardíaca, para avaliação clínica do controle autonômico do coração. Master's thesis,
Universidade de Brasília, Brasília, DF, Brazil.

9. Tsuji $\mathrm{H}$, Larson MG, Venditini FJ , Manders ES, Evans J C, Feldman CL \& Levy D (1996). Impact of reduced heart rate variability on risk for cardiac events. Circulation, 94: 2850-2855.

10. Reis $A F$, Bastos BG, Mesquita ET, Romêo Filho LJ M \& Nóbrega ACL (1998). Disfunção parassimpática, variabilidade da freqüência cardíaca e estimulação colinérgica após infarto agudo do miocárdio. Arquivos Brasileiros de Cardiologia, 70: 193200.

11. Kleiger RE, Stein PK, Bosner MS \& Rottman J N (1995). Time-domain measurements of heart rate variability. In: Malik M \& Camm AJ (Editors), Heart Rate Variability. Futura Publishing Company, Inc., New York.

12. Barbosa PR, Barbosa J \& Sá CAM (1996). Influência da idade, sexo e doença coro- 
nária sobre a modulação autonômica do coração. Arquivos Brasileiros de Cardiologia, 67: 325-329.

13. Hayano J, Sakakibara Y, Yamada A, Yamada M, Mukai S, Fujinami T, Yokoyama K, Watanabe $\mathrm{Y} \&$ Takata $\mathrm{K}$ (1991). Accuracy of assessment of cardiac vagal tone by heart rate variability in normal subjects. American J ournal of Cardiology, 67: 199-204.

14. Davy KP, DeSouza AC, J ones PP \& Seals DR (1998). Elevated heart rate variability in physically active young and older adult women. Clinical Science, 94: 579-584.

15. Psaty BM, Heckbert SR, Atkins D, Lemaitre R, Koepsell TD, Wahl PW, Siscovick DS \& Wagner EH (1994). The risk of myocardial infarction associated with the combined use of estrogens and progestins in postmenopausal women. Archives of Internal Medicine, 154: 13331339.

16. Hulley S, Grady D, Bush T, Furberg C, Herrington D, Riggs $B$ \& Vittinghoff $E$ (1998). Randomized trial of estrogen plus progestin for secondary prevention of cor- onary heart disease in postmenopausal women. J ournal of the American Medical Association, 280: 605-613.

17. Antila K (1979). Quantitative characterization of heart rate during exercise. Scandinavian J ournal of Clinical and Laboratory Investigation, 153 (Suppl): 13-58.

18. Malik M \& Camm AJ (1994). Heart rate variability and clinical cardiology. British Heart J ournal, 71: 3-6.

19. Malliani $A$, Pagani $M$, Lombardi $F$, Furlan R, Guzzetti S \& Cerutti S (1991). Spectral analysis to assess increased sympathetic tone in arterial hypertension. Hypertension, 17: III-36-III-42.

20. Marks BJ \& LighfootJ T (1999). Reproducibility of resting heart rate variability with short sampling periods. Canadian J ournal of Applied Physiology, 24: 337-348.

21. Sinnreich $R$, Kark J D, Friendlander $Y$, Sapoznikov D \& Luria MH (1998). Five minute recordings of heart rate variability for population studies: repeatability and age-sex characteristics. Heart, 80: 156162.

22. Marães VRFS, Silva E, Ribeiro TF, Petto J,
Moura MAS, Catai AM, Oliveira L, Trevelin LC \& Gallo J r L (1999). Study of heart rate variability in characterization of anaerobic threshold in discontinuous dynamic exercise tests. J ournal of Heart Disease, 1: 47 (Abstract).

23. Grady D, Rubin SM, Petitti DB, Fox CS, Black D, Ettinger B, Emster VL \& Cummings SR (1992). Hormone therapy to prevent disease and prolong life in postmenopausal women. Annals of Internal Medicine, 117: 1016-1033.

24. Rosano GMC, Patrizi R, Leonardo $F$, Ponikowski P, Collins P, Sarrel PM \& Chierchia SL (1997). Effect of estrogen replacement therapy on heart rate variability and heart rate in healthy postmenopausal women. American J ournal of Cardiology, 80: 815-817.

25. Christ M, Seyffart K \& Wehling M (1999). Attenuation of heart-rate variability in postmenopausal women on progestincontaining hormone replacement therapy. Lancet, 353: 1939-1940. 